\title{
Perception of Criminal Insecurity in Vulnerable Districts in Latin America
}

\author{
Macarena Rau ${ }^{1,}$, , Francisco Gatica ${ }^{1}$, Iván $\operatorname{Cartes}^{1}$, Thimothy Pascoe $^{2}$, Víctor Carrasco ${ }^{3}$ \\ ${ }^{1}$ Department of Urban Planning and Design, Bio Bio University, Concepción, Chile \\ ${ }^{2}$ Department of Criminology, Cranfield University, Cranfield, UK \\ ${ }^{3}$ Department of Political Science, Alberto Hurtado University, Santiago, Chile and Department of Anthropology, Christian Humanism \\ Academy University, Santiago, Chile
}

\section{Email address:}

mrau@pbk.cl (M. Rau), fgatica@ubiobio.cl (F. Gatica), icartes@biobio.cl (I. Cartes), tim.pascoe@griffinc.com.uk (T. Pascoe), vicarrascog@gmail.com (V. Carrasco)

${ }^{*}$ Corresponding author

\section{To cite this article:}

Macarena Rau, Francisco Gatica, Iván Cartes, Thimothy Pascoe, Víctor Carrasco. Perception of Criminal Insecurity in Vulnerable Districts in Latin America. Urban and Regional Planning. Vol. 4, No. 4, 2019, pp. 121-135. doi: 10.11648/j.urp.20190404.11

Received: August 4, 2019; Accepted: October 5, 2019; Published: October 26, 2019

\begin{abstract}
Latin America, the world's most criminogenic region from the perspective of intentional homicide, is also the region with the highest perception of criminal insecurity. This situation negatively affects the quality of life of its inhabitants, influencing their decisions on the use of certain public spaces or the possibility of avoiding them due to the fear of being victims of a crime. This comparative analysis of three cases of intervention through situational prevention strategies and Crime Prevention Through Environmental Design at the residential level, both in Chile and Honduras, seeks to establish the existence of a relationship between the socio-spatial modification of the environment and the impact generated from the implementation of these strategies in the levels of victimization, on the perception of insecurity and on the degree of social cohesion of the communities with which we work directly. To achieve this objective, a section was first developed with the main theoretical backgrounds related to Urban Security and the methodological proposal to measure the impact generated by situational prevention strategies and CPTED on intervened areas of the countries already mentioned. Then, the methodology used in this research is presented, which consists of three case studies with similar characteristics to each other, where each of these areas will also have their respective control group. It also includes the information collection techniques used, the design of the samples and the type of research to which this study corresponds. The analysis of the data allowed progress towards preliminary results, which are obtained mainly through the use of descriptive statistics, that is, by crossing variables relevant to the objectives of the research. While for the elaboration of conclusive results, inferential statistics were used through "chi-square", which led to the generation of statistically significant associations between variables, thus allowing evidence to be available impact generated by situational prevention methods and CPTED on the urban safety of the localities involved in both Chile and Honduras.
\end{abstract}

Keywords: Urban Security, Fear, Criminal Insecurity, Situational Prevention, CPTED, Latin America, Local and Neighborhood Scale, Crime

\section{Introduction}

Urban security has become a high priority on the public agenda of Latin American countries over the past decade, especially with regard to the increase in violent crime [1]. Crime prevention aims to reduce the environmental and social risk factors that cause criminal behavior and promote factors that protect against participation in antisocial or criminal activities, before they manifest behaviors. Although it tends to be confused with social policies in general, crime prevention is distinguished from them because it is not universally applied, but interventions and actions focus on groups of people and territories that are particularly vulnerable to Crime.

The homicide rate is the most widely used international indicator for comparing crime levels in several countries around the world. While the Latin American and Caribbean 
(LAC) regions have only $8 \%$ of the world's population, they account for more than $30 \%$ of the world's homicides. The homicide rate in $\mathrm{LAC}$ is four times higher than the international average.

A 2013 study by UNODC (United Nations Office on Drugs and Crime) indicates that intentional homicide in 2012 reached 36\% in the Americas, 31\% in Africa, 28\% in Asia; whereas in Europe (5\%) and Oceania $(0.3 \%)$ homicide rates were the lowest at the regional level. Although the global average of intentional homicides is 6.2per 100,000 inhabitants, South Africa and Central America show averages four times higher (more than 24 victims per 100,000 inhabitants), causing these sub regions to record homicides, followed by South America, Central Africa and the Caribbean (between 16 and 23 homicides per 100,000 inhabitants).

A result of this criminal phenomenon is found in the urban and architectural configuration of the cities of the central and South American sub region, given the formation of defensible enclosures or architecture [2] and where neighbors prefer to segregate spatially against the likelihood of being victims of crime or by the perception of high levels of insecurity.

Insecurity is one of the variables that would explain urban spatial segregation and closed communities, which has led to the formation of "urban ghettos" neighborhoods, compartmentalized and closed in themselves, with perimeter walls and other security measures such as electric fences and alarms, among others.

A number of factors in the urbanization process, including migration, productive change, the dissemination of innovations and population growth, some of them postulated as a result of the mix of cultures and inequality, are arguments that have proved insufficient as an explanation of the phenomenon and its increase - the results are a significant expansion of the forms of expression of anomic behavior, which are expressed in the prevalence of violence, the visibility of crime and, as a growing sense of insecurity, social estrangement, which is linked to the privatization of public spaces and the exponential increase of the automotive park, among other alterations that have led to a decline in the quality of life of the inhabitants of the cities [3].

\section{Theoretical Framework [4]}

However, there are theoretical concepts and guidelines of criminology and urban planning that provide an explanation and support. The situational and CPTED interventions used in this study are described below.

\section{CPTED}

One of the areas where the value of opportunity theory has been demonstrated is planning, urban development and architectural design. In Canada, the United States and other countries around the world, this approach is known as "Prevention of Crimes through Environmental Design" [5].

The concept of CPTED, coined in 1972 by C. Ray Jeffery, is based on the idea that crime occurs in certain spaces due to the location opportunities offered by the physical environment. This allows us to state that it is possible to alter this environment in such a way as to decrease the likelihood of such crimes occurring [6].

According to Jeffrey:

"The urban environment can influence criminal behavior in particular and behavior in general in two ways; physically, providing the physical environment to which individuals respond; providing the social relationships to which individuals respond. The most negative physical characteristics of the urban environment are noise, pollution and overpopulation. Social characteristics are alignment, loneliness, anxiety and dehumanization" [7].

The initial ideas of the CPTED propose four basic concepts: access control, natural surveillance, maintenance and territorial reinforcement. The first three are basically instrumental and common to other theories, while the fourth is linked to the theory of territoriality, which is part of ecological science. The advanced CPTED saw a fifth principle that is community participation.

Citizen security

While it is clear that crime and security issues have gained importance in recent years in the Latin American and Caribbean region, the concept of security and its different meanings need to be clarified. From a broad perspective, security is related to the set of systems for the protection of the life and property of citizens from the risks or threats caused by various factors, both psychosocial and developmental Urban. Conceptualized, security is linked to the social values of respect for life, physical integrity and the heritage of others, their economic, political and social freedoms [8].

To achieve citizen security, responsibility is required both from the State and its various organizations, as well as to the general public. In this sense, the active participation of citizens to overcome the problem of insecurity, through their community organizations, is essential to increase the levels of prevention and satisfaction of people.

The concept of citizen security has been commonly understood in two fundamental dimensions: firstly, as threats to people and property arising from criminal activities, in particular robberies with violence, theft and various forms of aggression; and second, the dangers associated with the occurrence of disasters caused by earthquakes, floods, ecological crises, among others.

\section{Social Prevention}

Social prevention is based on interventions with potential criminals, aimed at mitigating their criminal propensity, based on the classical theories of the aetiology of crime, according to which criminal action is explained by the existence of several risk factors identified in family, school, friends, couple, etc. As well as in secondary socialization agents such as employment, drug use and/or alcohol, etc.). In other words, it intends to act on the structures of crime and the creation of links of social solidarity which, by encouraging the prevention of illicit, increases the quality of life of citizens, where their results can only be observed in the medium and long term.

Crime

In this investigation, the concept of crime is specifically limited to a set of actions punished by law and that may affect 
individuals and/or property.

In the case of Chile, these crimes are defined as "Crimes of higher social connotation" (DMCS), as they constantly generate impact in the media and have recorded a rise in recent years, both in rate and in frequency.

The crimes of greater social connotation are divided into two groups:

a) Violent crimes: Robbery with violence, robbery with intimidation, robbery by surprise, injuries, homicides and rape.

b) Property crimes: theft of vehicles, theft in an inhabited place and other thefts with force.

\section{Situational Prevention}

Situational prevention has become a key axis in public policy and research since the early 1980s in several countries around the world. This coincided with a favorable political and academic situation in the United Kingdom, the United States and Australia, countries where it has expanded the most since [9].

In this sense and specifically, the development of a situational approach to crime prevention, with theoretical basis and empirical research, is strongly linked to the work of the Urban Planning Unit of the Ministry of the Interior, United Kingdom, to early 1980s, and especially with the work of criminologist Ronald Clarke.

In criminological terms, situational prevention represents a path to:

1. Prioritization of crime prevention to act through practical and less academic oriented policies.

2. An emphasis on alterations in the physical environment.

3 . The relevance of the informal social control process.

Perception of Crime Insecurity

There are several theories that support the perception of criminal insecurity. These include theories of incivility, victimization, physical vulnerability, social vulnerability, and social media. Although some of these theories are partially related, either in their causal mechanisms or in the indicators that have been used to test them, they all have distinctive elements [10]. The perception of insecurity in the face of crime is subjective and connects in every human being with the instinct of survival and the fear of death. Depending on the territory and the affected community, they may differ from the crime that is an objective fact [11].

Fear of Crime

Fear of crime and citizen insecurity would not have the same meaning, since although fear of crime, such as the perception of insecurity, would refer to subjective perceptions and emotions of individuals (San Juan, Vozmediano \& Vergara, 2013). However, fear of crime refers to the fear of citizens to be personally victims of a crime or a certain type of crime, while citizen insecurity can be understood as a fear of crime in the abstract, i.e. the crime is a concern as a social problem [12].

Thus, citizen insecurity would not only include crime as such, but also "other concerns such as terrorism, the presence of immigrants, food security, and now, with torrential hatching, the fear of climate change".
Secondly, a differentiation can be made between concern for crime and fear of crime as such. In this regard, the concern for the crime would relate to the general view of the general public's view of the seriousness of the problem of crime, based on the official data available. However, fear of crime as opposed to this term is not based on data but on the perception of each citizen of his or her own chances of being a victim, as has already been mentioned.

\section{Research Question}

Crime affects all levels of society in different ways: men and women, young and old, rich and especially the poorest. The economic costs of crime are extremely high. The most recent comparable estimates indicate that Latin America and the Caribbean (including 32 countries) is the region with the highest average homicide rate, 27.5 homicides per 100,000 inhabitants; It is followed by Africa with a rate of 22.2, while the global average is 8.8 homicides per 100,000 inhabitants [13].

Crime and urban violence also create a climate of widespread fear that results in serious threats to the social stability of cities, economic and sustainable development, quality of life and human rights. Children and adolescents are the most vulnerable to violence, being disproportionately represented as victims, aggressors and/or witnesses.

In this context, the following research questions are raised:

Do situational prevention interventions and CPTED lead to a reduction in the perception of crime insecurity? And if it's true;

What social and/or environmental variables cause this reduction?

\section{Methodology}

To answer the questions raised, 3 case studies with similar characteristics regarding social, environmental and criminal vulnerability are chosen. The first is located in the town of Tela in Honduras, the second in the municipality of Puente Alto in Chile and the third in the city of Coyhaique, in Chilean Patagonia.

These cases have high rates of crime, and the population also distrusts the institutions of government, order and security in the three territories surveyed. In addition, there is a limited period of time for measurements using the ESU questionnaire in the different areas covered for the collection of quantitative information. Therefore, it was decided that to answer research questions, a quasi-experimental research design would be used, which uses prior and subsequent time periods and areas of action/intervention and control.

Quasi-experimental designs deliberately manipulate at least one independent variable to observe its effect and relationship with one or more dependent variables, and differ only from "pure" experiments in the degree of safety or reliability that can be to be held on the initial equivalence of the groups [14].

In this research the subjects were not randomly assigned to the groups or were matched, but that these groups were 
already formed according to common characteristics of their members from before the experiment: they are intact groups (the reason they arise and the way as they were formed is independent or apart from the experiment). In this case, the groups in this study correspond to social leaders and/or community leaders trained prior to the measurement and each constitutes an experimental group.

The choice of a set of persons whose common characteristic is to represent the neighbors in each of the territories considered for the realization of the measurements, corresponds to a type of intentional or judged sampling, since the samples are selected mainly based on the knowledge and credibility of researchers. In other words, researchers have chosen those they believe to be appropriate (with respect to the attributes and representation of a population) to participate in this study.

The dependent variables that were measured are the perception of criminal insecurity in both Honduras and Chile, both countries with high crime rates and high levels of insecurity. Independent variables are those associated with Situational Prevention and CPTED projects that are built in vulnerable neighborhoods, such as luminaire location, alarm installation, paving, playground installation, and among other.

To identify these groups of independent variables linked to a Situational Prevention and CPTED project, three levels of intervention (urban configuration, community participation and local governance) linked to the project are defined:

Scope 1: Urban Settings.

In this area, the CPTED methodology is linked to variables defined according to 5 fundamental principles:

a) Natural surveillance: lighting, natural guards, visual fields, formal surveillance, luminaires.

b) Territorial reinforcement: muralism v/s graffiti, territorial marks in commerce and equipment, territorial marks on private property.

c) Natural access control: urban access, residential steps, alarms.

d) Maintenance: vandalism and abandonment, signage.

e) Community participation: neighbors or residents.

Scope 2: Community Participation [15].

a) Occupation of the public space residents.

b) Participation of neighbors in the design of the situational prevention project.

c) Interactions and games of children and young people.

Scope 3: Local Public Management.

a) Municipal coordination meetings.

b) Mobile phones in the neighborhood.

c) Police operations.

d) Police station in the neighborhood.

\subsection{Sample Design}

The sample design of this study is of a non-probabilistic type, since the samples were selected based on criteria defined from the limited times for the collection of quantitative information, and according to the need to obtain information from people representing much of the residents of the territories where the surveys were conducted.
Within this quasi-experimental longitudinal research design, the experimental and control groups were chosen using the paper design technique, which consists of observing the social leaders of Tela, Puente Alto and Coyhaique, whose socio-economic characteristics are similar, as they reside in similar environmental contexts and in all three cases, the intervened and control group are adjacent to each other.

In this way, the security perception was measured in the time before and after the implementation of situational methodologies and CPTED in the case of experimental groups, and the results were compared with the data obtained in the sectors where they were not performed these environmental changes.

It is important to mention that the objective of this research is to be able to develop a comparative analysis and measure the impact that is mainly generated on the perception of communities that are intervened through situational prevention methods and/or CPTED, to contrast this effect with the reality of control groups in contiguous sectors, which have similar socio-cultural and socio-environmental characteristics, but which have not been intervened through the prevention strategies of the crime mentioned above.

Unlike the data that criminal statistics of certain territories can provide, which can be compared in different periods of time, i.e. prior to and after environmental design interventions, the use of ESU questionnaire as a quantitative information collection tool is even more relevant than the sources mentioned above, since in general in Chile the percentage of cases where people do not report crimes is $60 \%$ [16], so the impact of prevention strategies could be affected depending on the number of complaints made by the population.

On the other hand, in Honduras people distrust institutions of order and security, as well as institutions of political, economic and judicial influence, so the implementation and evaluation of situational prevention strategies and CPTED by external or international agencies contribute to building trust. of the community, generating that people answer the questions posed more sincerely, so that the information obtained through the ESU questionnaire can reach higher levels of honesty and transparency, generating results that are really research objectives, which seek to know if there is a reduction in the perception of population insecurity against crime through the implementation of situational prevention methodologies and CPTED unlike other sectors with similar characteristics where such interventions have not been developed, considering further that this perception of insecurity is subjective and connected in every human being, depending on the territory and community where the measurements are made, so that this questionnaire facilitates such work in terms of data collection and contributes to the development of qualitative tools as needed to give greater depth to the measurements made through the surveys.

While, in this type of sampling not all the inhabitants of the community had the same chance of being chosen for the application of the ESU questionnaire, as it is an exploratory study, it nevertheless allows to collect valuable information from a significant number of social leaders and community 
leaders, both from the areas intervened and also from the territories observed as control groups.

The samples were designed to implement the first surveys in the neighborhoods of Chile and Honduras in 2016. During that year, in Chile, 63 surveys were applied in the commune of Puente Alto, of which 30 were taken in Pedro Aguirre Cerda (PAC), which CPTED attended, and 33 in a group of adjoining populations that were used as a control group without intervention. In 2017, 30 surveys were reapplied in Puente Alto, 15 in PAC during the month of November, after the population was intervened a second time through CPTED projects, and 15 questionnaires were applied in the control group, so in total there are 93 surveys applied to community leaders in the commune of Puente Alto.

In Coyhaique commune, 40 surveys were applied in 2017; 20 in the sector of Quebrada La Cruz where a CPTED intervention had been initiated, and 20 more in the sector of Quebrada Las Lumas as a control group. Meanwhile, during 2018, 30 new instruments were applied under the Sample Selection Criteria mentioned above, 15 in the population that had intervention through CPTED methodologies and 15 in other Coyhaique sectors, so it was achieved reach a number of 70 surveys of key players in this commune in Chile.

In the case of Honduras, a total of 101 surveys were applied during 2016 and 2017. In the neighborhood of La Laguna, which was involved with a CPTED project, 50 measurements were made through the ESU questionnaire, while in the sector of September 15, in an area used as a control group, 51 surveys were applied to social leaders. In both cases, the measurements were divided into two phases, before and after the intervention.

In short, the sample was sought to simplify fieldwork, taking into account for the purposes of this research, the application of the ESU questionnaire to community leaders, as well as to social leaders, as they are those who live together and try the times and daily ones with the problems arising from insecurity in the sectors where they reside, being those who can through this survey, convey what their relatives, neighbors and friends perceive about the level at which the crime affects the Quality of life of the Community.

Table 1. On sample distribution for the application of the ESU questionnaire according to intervened territory and control group.

\begin{tabular}{llll}
\hline Experimental group & Sample & Control group & Sample \\
\hline Pedro Aguirre Cerda & 45 & Another sector of Puente Alto \\
Clotario Blest & 35 & Santiago Vera Cartes & 48 \\
La Laguna & 50 & Another sector of Coyhaique & 18 \\
Total cases & 265 & 15 de Septiembre & 18 \\
\hline
\end{tabular}

To this quantitative information, qualitative information is added that is raised in all the neighborhoods intervened with CPTED, obtained from the application of the following instruments: MES (Exploratory Security March), Workshop on Drawings and Observation Direct of the Expert through photographs of the project (describes urban configuration from the CPTED methodology).

Samples of this qualitative information are detailed below:

Table 2. On sample summary for qualitative information collection techniques by period and territory.

\begin{tabular}{llllllll}
\hline \multirow{2}{*}{ Commune/Year } & \multicolumn{2}{l}{ Exploratory march } & & \multicolumn{2}{c}{ Drawing workshop } & \multicolumn{2}{c}{ Asambleas: Entrevistas/Focus group } \\
\cline { 2 - 7 } & $\mathbf{2 0 1 6}$ & $\mathbf{2 0 1 7}$ & $\mathbf{2 0 1 8}$ & $\mathbf{2 0 1 7}$ & $\mathbf{2 0 1 8}$ & $\mathbf{2 0 1 6}$ & $\mathbf{2 0 1 7}$ \\
\hline Tela & - & 20 & - & 15 & - & - & 35 \\
Puente Alto & 20 & 20 & 20 & 30 & - & 30 & 21 \\
Coyhaique & - & 38 & 20 & 45 & 40 & - & 35 \\
\hline
\end{tabular}

\subsection{Stages for the Design of the Impact Measurement Methodology}

Through the development and implementation of different information collection techniques, whether quantitative or qualitative in nature, this research seeks to advance knowledge on how to assess the impact of CPTED and situational prevention in the Latin American and Caribbean region; particularly with regard to the phenomenon of urban insecurity and crimes of greater social connotation.

It is interesting to deepen scientific knowledge by developing an impact assessment methodology of situational prevention strategies and CPTED in crime-vulnerable neighborhoods and the perception of fear in Latin America.

A key part of achieving crime-free environments is to share success stories that have scientific evidence, that measure and demonstrate measures that work and those that don't. Currently, there is no methodology to measure and evaluate situational and CPTED prevention interventions in Latin America and the Caribbean, so this evidence is not yet available at the regional level. This research seeks to build this methodology, so that programs with situational prevention strategies and CPTED are still implemented, but that can henceforth be evaluated their results.

Variables of urban configuration, community participation and local public management, in addition to the cross-cutting items of victimization and perception of insecurity, constitute the main axes of the questionnaire component of the evaluation methodology impact. This was tested in three neighborhoods whose common characteristic is their social vulnerability and high crime rates, and which in turn have been tapped with situational prevention methodologies and CPTED. In addition, each of these neighborhoods was controlled by a neighborhood that had no intervention.

It is important to mention the main objective of the impact measurement that is sought in this study, seeks to determine 
whether the situational prevention project or CPTED as the case may be, have produced the desired effects, ruling out explanations Alternatives. For this, it is necessary that the impact assessment is capable of providing scientific evidence that there is no independence between the contrasted variables, and that there is an association between the implementation of prevention programs and the effects found. In addition, it is currently recommended that the implementation of citizen security policies be evidence based on their effectiveness and that impact assessments be included.

\subsubsection{International Methods of Evaluation of Crime Prevention Programs}

There are currently few impact assessment methodologies for prevention programs worldwide. From the bibliographic review stand out two methods of evaluation of prevention programs that contribute to research, which are the SARA method and 5ls Framework, considered to be the most relevant. In addition, the 7-step model is incorporated for a successful crime prevention program (Beccaria Program).

From the following summary table, it is possible to conclude that the first two models, namely SARA and 5Ls Framework, are closer, and that 5Ls complements the elements of the first, which is mainly reflected in the fact that SARA does not consider processes participations, while 5Ls has a phase of involvement with people and institutions linked to the implementation of the prevention program in a specific territory [17].

5Ls is a more detailed prevention program evaluation model than SARA, so it can be adaptable to other areas given its flexibility, being able to work with more complex elements, thus helping to clarify problems for the selection of appropriate strategies and replicate such actions in different contexts, being able to incorporate the innovation component when circumstances so require.

\begin{tabular}{|c|c|c|c|}
\hline Method & SARA & 5ls Framework & \multirow[b]{2}{*}{ 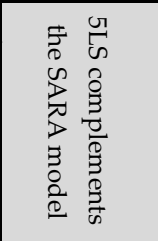 } \\
\hline 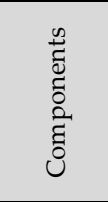 & $\begin{array}{r}\text { Scanning } \\
\text { Analysis } \\
\text { Response } \\
\text { Assestmen }\end{array}$ & $\begin{array}{l}\text { Intelligence } \\
\text { Intervention } \\
\text { Implementation } \\
\text { Involvement } \\
\text { Impact }\end{array}$ & \\
\hline Method & \multicolumn{2}{|c|}{ Beccaria Program } & \\
\hline $\begin{array}{l}\text { \& } \\
\text { 足 } \\
\text { I }\end{array}$ & $\begin{array}{l}\text { 1. Describe and } \\
\text { 2. Identifi the c } \\
\text { 3. Define object } \\
\text { 4. Devolpment } \\
\text { 5. Design and i } \\
\text { program plan } \\
\text { 6. Impact revie } \\
\text { 7. Documentati }\end{array}$ & $\begin{array}{l}\text { theme } \\
\text { ible solutions } \\
\text { entation of the } \\
\text { l conclusion }\end{array}$ & 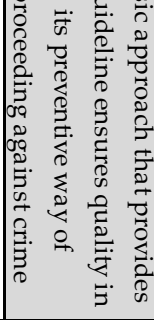 \\
\hline
\end{tabular}

Figure 1. On comparative international methods of impact measurement. Own elaboration, based on the review of bibliographic sources.

The Beccaria project, for its part, seeks to establish quality standards with regard to preventive actions that are developed around the subject of crime, these attributes must ensure that these measures point to specialized science and literature, which can be evaluated based on their effectiveness and the quality of their projects [18].

In short, and for the purposes of this research, it is essential to indicate that the methods of evaluation of Crime Prevention Programs above complement each other, and that the use or choice of a particular model will vary depending on the objectives, needs and resources available, taking into view of the context, the applicant's indications and a number of variables which will contribute to the decision-making.

\subsubsection{Synthesis of the Methodological Impact Assessment Process of Situational Prevention Strategies and CPTED}

Components of the methodology:

1) Baseline and diagnostic

a) Collection of diagnostic information: In this first stage, primary and secondary information is collected from the territory where the central or local government conducted a situational prevention intervention and CPTED to form a baseline and Diagnostics. Unlike the international models studied above, this methodology considers criminal information prepared by reliable sources, but in turn builds its own information from the application of the ESU questionnaire.

b) Application of the questionnaire: Primary information considers the definition of dependent and independent variables. Dependents are of the criminal phenomenon (e.g. homicide, theft, drug sale, perception of fear, among others). Independent variables, meanwhile, respond to the areas of urban configuration, community participation and local governance. For this purpose, the survey instrument developed is applied.

Added to this is qualitative information obtained from the application of the following information collection techniques: MES (Exploratory Safety March), Drawing Workshop, Perceptual Map and Direct Observation of the Expert.

c) Development of the Exploratory March (MES), a workshop on drawing and direct observation: Secondary information is raised regarding intervention from the social, urban and criminal fields.

d) Control group: The collection of primary and secondary information should be carried out both in the intervened population and also in areas acting as control groups and located in sectors adjacent to the former, where they are also considered, similar socio-environmental features. In this sense, it is relevant to clearly define what the control variables will be.

e) Baseline construction: The case information for the first measurement is systematized and organized according to the three study areas:

i. Victimization and perception of fear.

ii. Social media. 
iii. Spatial configuration and local management.

2) Data analysis

Primary and secondary information is processed, databases are built, and variables are crossed for further analysis using Excel, SPSS, or similar Software. This provides information to demonstrate through Pearson's chi-square hypothesis tests the relationship between the dependent and independent variables that are part of this study.

3) Design of the strategy

Once the information has been obtained, it is essential to share it with the respective municipal teams to contrast it, supplement it and verify it with those officials who work directly with the people, and most relevantly, in contact with the Citizenship.

4) Implementation of the strategy

After the validation of the results obtained in the first measurement with respect to the incidence of independent variables on dependents in the context of situational prevention, new strategies should be incorporated into the project that has been developed or that is in the process in the territory (for example in the case of PAC, the survey shows that the spaces of greatest victimization are the streets and whereabouts of collective locomotion, so the municipal team decides to install more pedestrian luminaires in spaces.

5) Evaluation

Where considerable progress has been made with the implementation of the situational and CPTED strategies, the second measurement should be made, re-considering the same sample universes and measuring instruments (ESU, MES, Direct Observation), among others.

6) Response

The response actions of the modified strategy are implemented once the independent variables that preferably act on the criminal phenomenon have already been identified.

\subsubsection{Methodology Scheme}

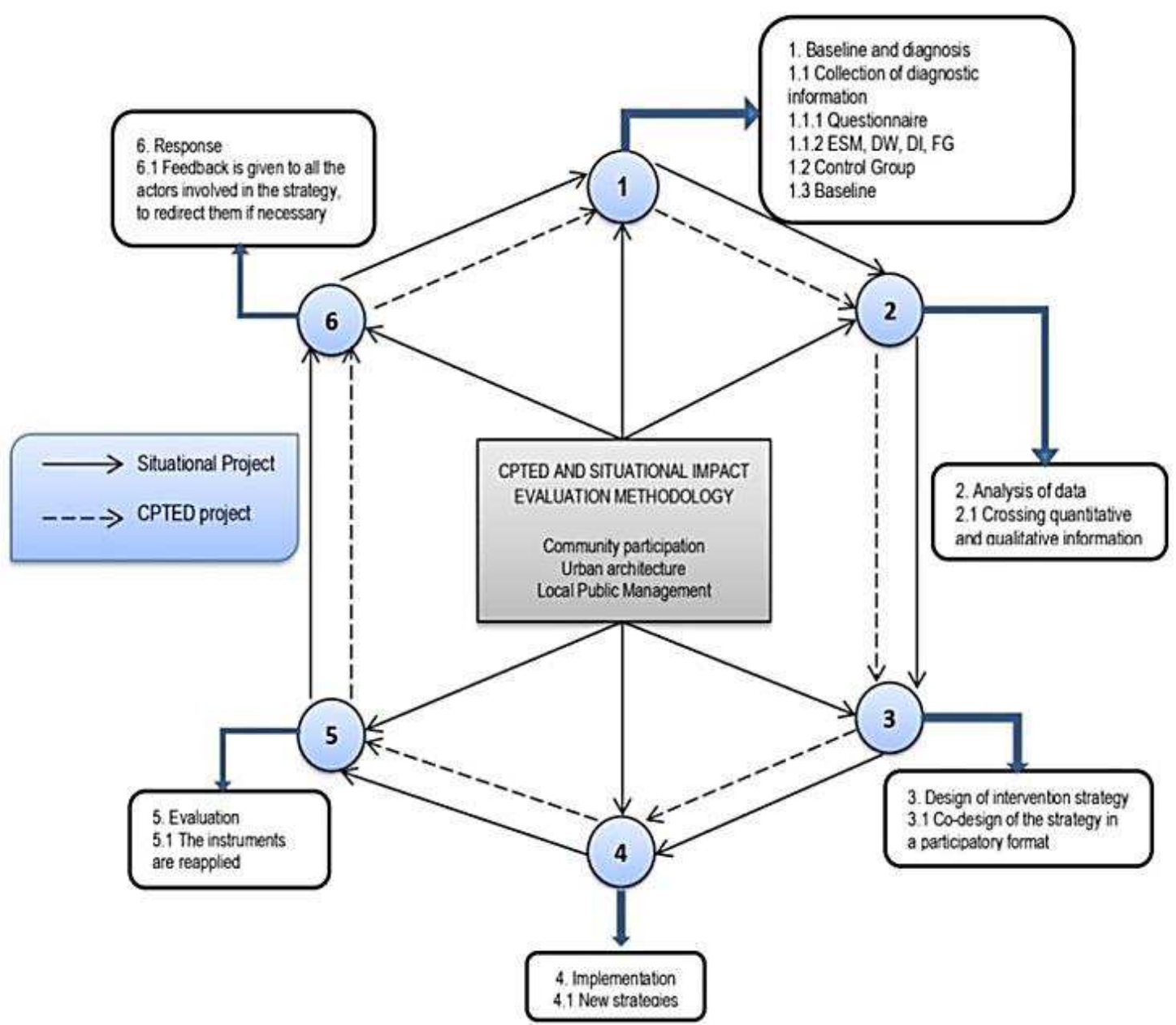

Figure 2. On Scheme on the methodology of impact evaluation of situational projects and CPTED.

\subsection{Implementation Recommendations and Limitations}

a) Training and introductory talks are recommended in the impact assessment methodology of situational prevention strategies and CPTED to contracting teams, whether municipal, national or private.

b) The different phases of the methodology set out above must be explicitly clarified, in particular as regards the quality of the information, the participatory processes and the times that its implementation may take. This fact 
can remedy the problems arising from the short time for the lifting of quantitative information, improving the organization and detailing certain items of the questionnaire, in order to develop in future measurements, tests with samples under designs those that achieve higher levels of representativeness.

c) It is essential to regularly report to the municipal council or a similar body at the national or private level, on the results obtained through the various longitudinal measurements in the field, as well as the adjustments to the methodology over time.

d) One of the limitations in this particular case relates to the fact that because the time for the application of the ESU questionnaire in the different territories was quite brief, and the instrument itself in a first version was quite extensive, a quasi-experimental study was chosen, i.e. where the sample assignment is not done randomly, so designs may lack absolute experimental control of the relevant variables due to the lack of randomization, either in the random selection of the subjects or in the assignment of them to the experimental and control groups.

Despite the above, the method used at this time is particularly useful for studying problems in which you cannot have full control of situations, but in which you are intended to have as much control as possible.

\section{Object of Study}

Three cases were chosen for this investigation; all of them with vulnerable factors in social, environmental and criminal areas, as described below.

\subsection{Pedro Aguirre Cerda (PAC in Metropolitan Region, Santiago, Chile)}

The Pedro Aguirre Cerda area (PAC) is located in the western sector of the Puente Alto district in Santiago de Chile, between the streets; Concha y Toro, Covadonga, Abate Molina and Ramón Barros Luco. It has peripheral population characteristics; this means little accessibility to public transport and services. Includes populations such as; P. A. C 1, P. A. C 2, Oscar Bonilla and María Magdalena, which recognize a significant impact on the occurrence of drug and microtrafficking crimes, as well as their incidence and consumption [19].

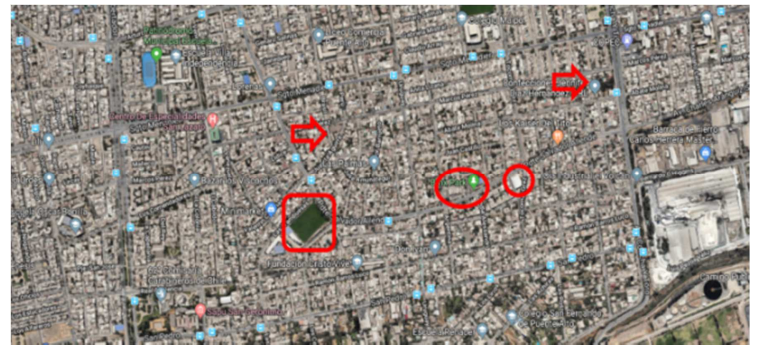

Figure 3. Corresponding to Pedro Aguirre Cerda area, Puente Alto. Santiago, Chile.

In addition, this area has a population of approximately 809 inhabitants, most of which are concentrated in the age range between 11 and 17 years.

\section{CPTED interventions}

In 2014, a square and a multi-court were recovered in a sector that the community calls "La Calama". For families in the sector, the recreational and sports field with the Skate track is key to responding to community needs and social cohesion. In addition, the neighbors requested, during the participatory process, that the luminaires in the area be replaced and that children's games be installed. To this day, community workshops are held with the assistance of the municipality every 15 days as a complementary service to the new infrastructure.

Neighbors requested in August 2016 the change of lights on the main streets of Salvador Allende, the pruning of trees and the improvement of the pavements of passages. These changes were made by the municipality in October 2016. After these changes, a new evaluation process was applied using the Impact Assessment Questionnaire (ESU).

\subsection{Tela}

The neighborhood of La Laguna was created in 2002, has a population of 153 inhabitants and is located in Tela, Honduras. It has a size of $22,498.80 \mathrm{M} 2$. It is bordered to the north by the September 15 area, the El Retiro to the south, the Las Lomas to the east, and the Hiland Creek and Hiland Creek neighborhood to the west.

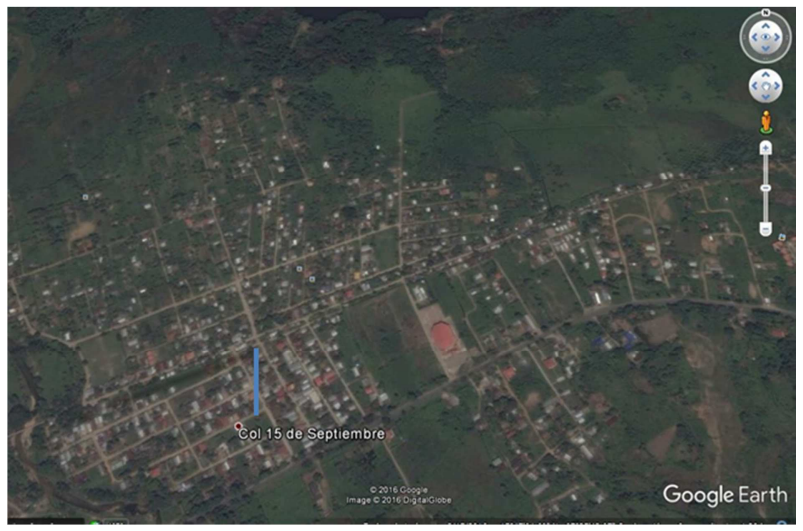

Figure 4. Corresponding to the sector of La Laguna. Tela, Honduras.

\section{Situational Interventions}

In 2016, seven public lamps were replaced on the main street, increasing the visual fields. For these interventions, exploratory marches were carried out with the neighbors. In addition, the situational intervention was performed after the initial measurement of the baseline.

\subsection{Coyhaique}

Quebrada la Cruz, where the CPTED Park Project is located in Coyhaique, capital of the Chilean Patagonia region, is surrounded by the populations of SERVIU, located without an urban criterion of unity between them or a quality public space for the people can strengthen social cohesion, and at heart, without offering comprehensive alternatives taking into 
account the quality of life of its inhabitants.

Quebrada la Cruz, where the CPTED Park Project is located in Coyhaique, capital of the Chilean Patagonia region, has a population of 1,572 inhabitants, and is surrounded by SERVIU areas, which have been located without an urban criterion of unity between them and without adequate public spaces for people to develop social cohesion, which does not offer comprehensive alternatives for improving the quality of life of the inhabitants of that area.

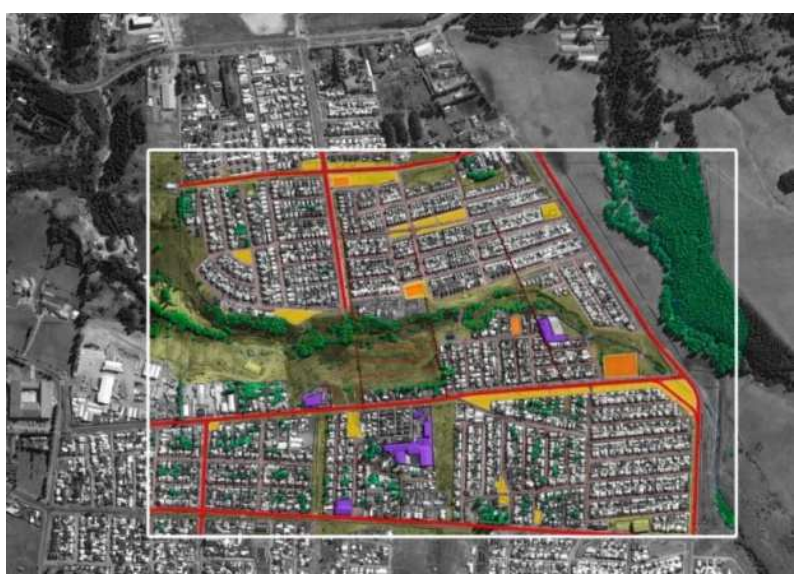

Figure 5. Corresponding to the sector of Quebrada La Cruz. Coyhaique, Chile.

\section{CPTED interventions}

The relevance of the transsectoral, pedestrian and vehicle connections, made within the master plan of a park project that is responsible for an appropriate design for the La Cruz estuary, was a high priority for the application of the CPTED methodology, allowing accessibility and connectivity of vehicles and demonstrating the importance of pedestrian connections.

The vehicular connection project must necessarily be proposed in conjunction with the park project, responding to a larger design strategy, which considers the sector on an urban scale and which draws on an intense process of community participation. Intervention proposals should be generated, incorporating different design alternatives, to clearly identify the benefits and difficulties they should work with; Proposals that will be addressed by the municipality. So far, CPTED's work with the community has identified environmental situations that increase the perception of fear and the criminal opportunity of users.

From the master plan of intervention until today 15 lamps of a pedestrian route were installed by the municipality with a strong participatory process.

\section{Results}

The research showed some interesting results that will be described below.

Coyhaique has a history based on data collected in 2017-2018, where it is noted that during the first measurement $16.7 \%$ of respondents were victims of a crime during the last twelve months. In this town, there is an increase in crime of $1.5 \%$ during 2018, which has an impact on the Clotario Blest population, where no cases of crimes were reported during the first phase, but where the victims were observed to reach $18.8 \%$ of the total respondents in the observation (see chart 1).

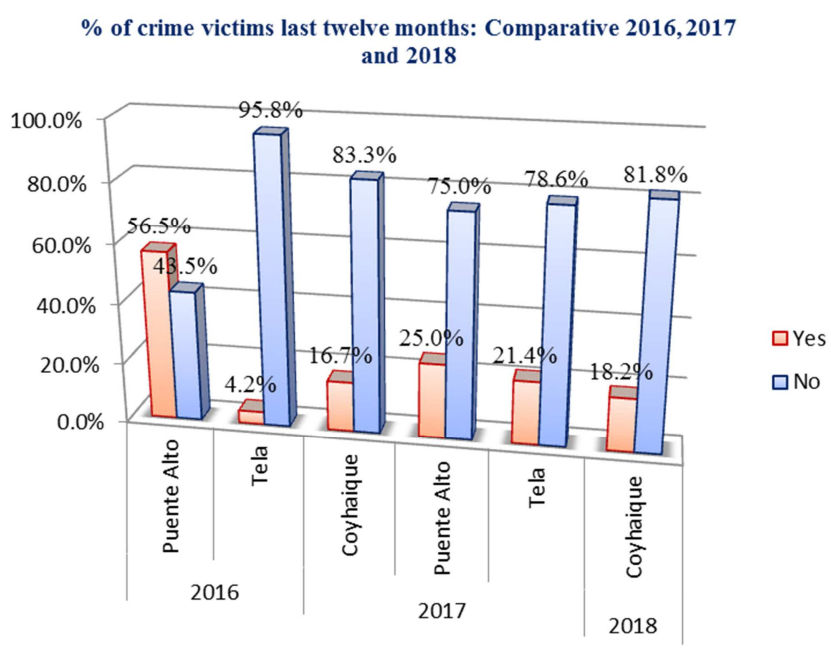

Figure 6. On crime victims last twelve months. Comparative 2016, 2017 and 2018. Source: Victimization questionnaire, perception of insecurity and environmental variables (ESU).

In Puente Alto, during 2017 there is a decrease in the number of people who claim to have been victims of a crime in relation to 2016 , with a variation of $-31.5 \%$.

Finally, the municipality of Tela, in Honduras, showed an increase of $12.5 \%$ in 2017 compared to the same period of the previous year; however, it remains the commune with the lowest number of victims of crime, both for 2016 and for 2017.

Type of crime before and after intervention

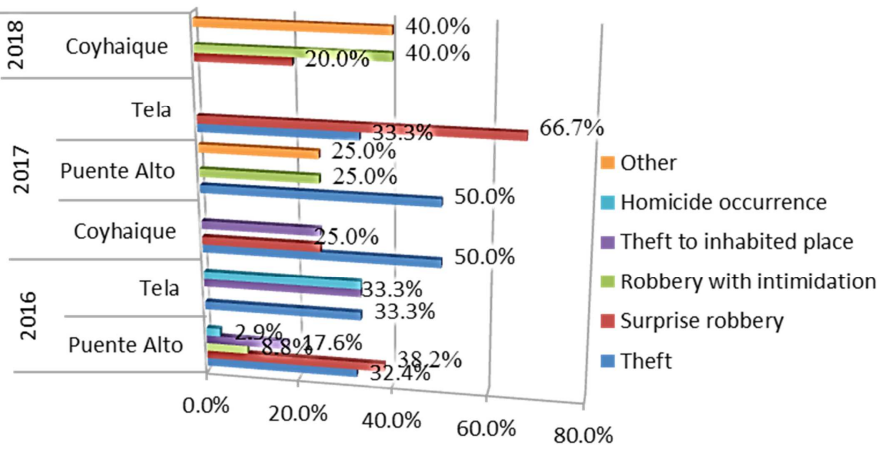

Figure 7. On macro-sector crime type before and after situational interventions and CPTED. Data compared to 2016, 2017 and 2018. Source: Victimization questionnaire, perception of insecurity and environmental variables (ESU).

With regard to the type of crime recorded from the collection of information through the Questionnaire of the ESU, in the commune of Puente Alto, it is noted that in 2016 thefts by carelessness and violent ones prevail, since as a whole they both reach a tot percentage $70,6 \%$. After the intervention, the most recurrent crime observed in Figure 2 in 
this macro area of Santiago is exclusively theft by carelessness $(50 \%)$, however, it remains the only criminal act recorded in this commune that is generated from an "opportunity" for the thief, placing the robbery with intimidation second, stating that the criminals, once situational prevention measures and CPTED were implemented, required greater violence in their actions to carry out their crimes.

Meanwhile, in Tela, during 2016, the crimes that affected the respondents were distributed in equivalent percentage between robbery, robbery in the inhabited place and homicides, where many people reported having witnessed or heard about the occurrence of these latest events.

After the intervention, violent crimes linked to homicides were reduced to zero, as were cases of thefts inside private compounds.
Finally, in the commune of Coyhaique, during the first application of the ESU questionnaire, $100 \%$ of the crimes corresponded to thefts of different types, i.e. robberies $(50 \%)$, robberies by surprise $(25 \%)$ and robberies to inhabited places (25\%) In the second measurement, as in the case of Puente Alto, when implementing improvements in the environmental infrastructure of the territories, there were crimes that require a higher level of violence by criminals, where the crime of theft with bullying increased by $40 \%$ between 2017 and 2018 .

The following table (number) shows the specific locations where the crimes that affected the persons surveyed during the twelve months prior to the application of the ESU questionnaire have occurred most frequently in the three measurements carried out.

Table 3. On the specific location where the crimes occurred. Data compared 2016, 2017 and 2018. Source: Victimization questionnaire, perception of insecurity and environmental variables (ESU).

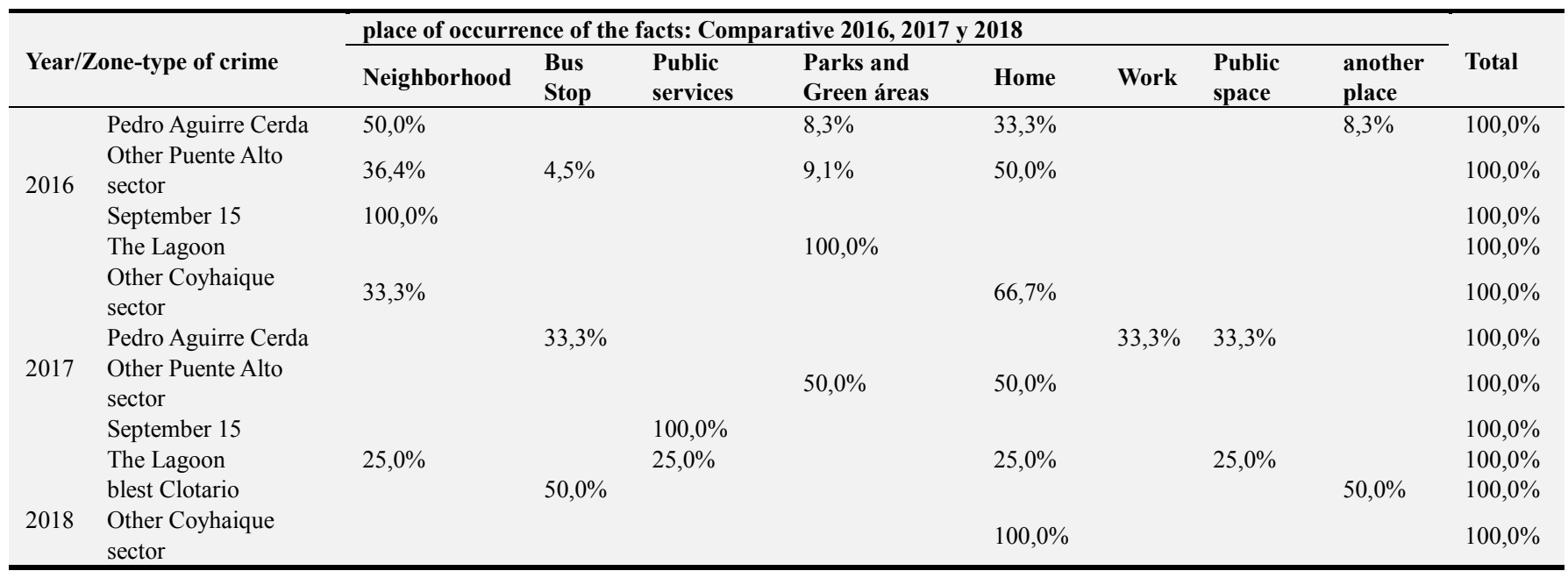

According to the figure above, in the Pedro Aguirre Cerda de Puente Alto population, in $201650 \%$ of the crimes occurred inside the neighborhood, while $33.3 \%$ occurred inside the home.

After the intervention carried out using the CPTED methodology in the different areas of the territory, in 2017 the crime moved to the whereabouts of collective locomotion, to the workplaces and other public spaces outside the sector of residence.

In La Laguna, meanwhile, in 2016 all the crimes that affected community leaders and social leaders in this sector, occurred in parks, squares, other green areas and/or in recreational places or for sports activity. In 2017, meanwhile, after the implementation of situational prevention strategies in the area, the crime was dispersed to different places in the public space, to government units and to people's homes.

In the case of Clotario Blest in southern Chile, in 2017 there were no crimes of greater social connotation, whereas after the intervention by CPTED, in 2018 the criminal acts were mainly concentrated in the whereabouts of locomotion collective and in remote locations.

In the graph below, we can see that there is a significant increase in confidence among the neighbours of the three polled sectors in the event of a risk or danger to the community following the implementation of methodologies situational prevention and/or CPTED.

Figure 3 shows that in the PAC population of Puente Alto, during 2016, the percentage of confidence in the neighbors reached $66.7 \%$, increasing according to the data of the second measurement to $100 \%$.

Existence of vandalism in the area of residence

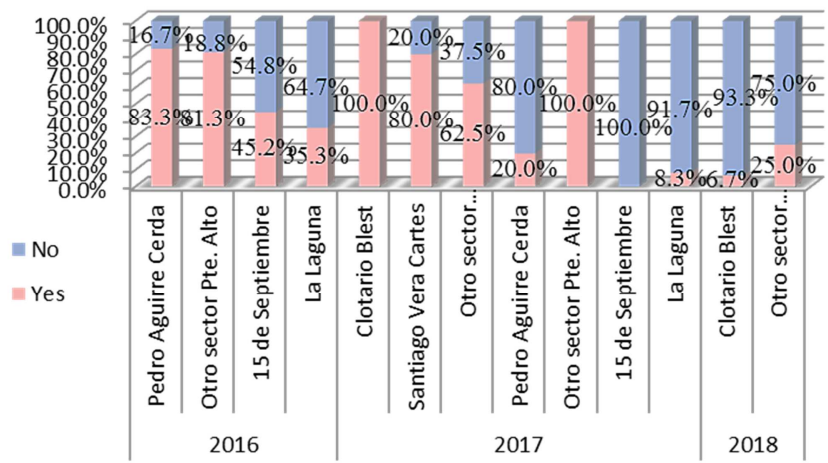

Figure 8. On vandalism in the sector where respondents live. Data compared to 2016, 2017 and 2018. Source: Victimization questionnaire, perception of insecurity and environmental variables (ESU). 
In the colony of La Laguna in Honduras in meanwhile, in the first instance the people in this area who indicated trusting their neighbors were about half of the respondents, while in 2017 that percentage increase to $100 \%$ as in the case of Pedro Aguirre Cerda.

Finally, in Clotario Blest de Coyhaique, the percentage of confidence between the residents of the territory in the event of emergency and/or danger, increased by $10.5 \%$ after the improvements made in the of urban infrastructure.

According to the graph above, vandalism was reduced in the three areas where situational and/or CPTED prevention methods were implemented. This, given that in the PAC population of Puente Alto, respondents who reported vandalism in their home sector went from $83.3 \%$ to just $20 \%$ on the second measurement; while in the La Laguna colony this percentage decrease was $27 \%$.

In the Clotario Blest sector meanwhile, the number of respondents who claimed the existence of vandalism in the first survey was $100 \%$, after the CPTED intervention that percentage was reduced to a minimum $6.7 \%$, so the development of these prevention strategies in addition to reducing the occurrence of these facts and improving the perception of security, provide the conditions for better coexistence and social cohesion.

As mentioned recently, the implementation of situational prevention and CPTED programmes, as seen in the two measurements made by each of the areas intervened, has managed, among other things, to develop spaces for participation social cohesion between neighbours (see Figure 5).

As shown in Figure 5, in the Pedro Aguirre Cerda de Puente Alto population, according to the perception of social leaders, community participation in neighborhood improvement programs increased from $30 \%$ in 2016 to $50 \%$ in 2017 , while in the La Laguna sector this increase was $61.3 \%$ to $92.3 \%$ in the same period.

Participation in neighborhood improvement programs

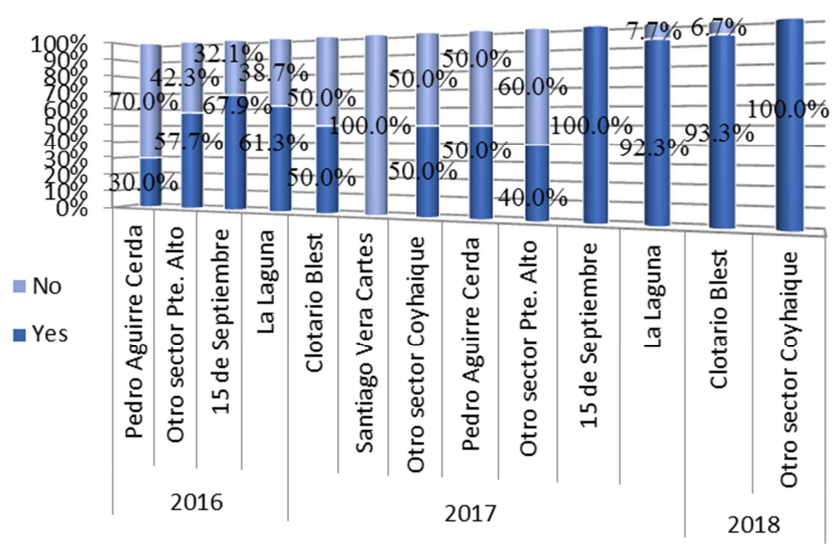

Figure 9. Percentage of citizen participation in urban infrastructure improvement programs. Data compared to 2016, 2017 and 2018. Source: Victimization questionnaire, perception of insecurity and environmental variables (ESU).

In the Clotario Blest sector, the increase in the participation of neighbours in the different strategies for the improvement of the environmental design of this town, was $43.3 \%$, that is, almost all of the people surveyed in the second measurement reported being permanent participants of programs and projects aimed at developing infrastructure and security improvements in the neighborhood where they reside.

In short, while interventions using situational prevention methodologies and CPTED have not translated categorically into a decrease in the number of crimes according to the data in this study, a fact that may otherwise be due to the increase in reports of increased levels of public confidence towards community safety and protection agencies, the above-mentioned interventions if they have succeeded in hindering the action of criminals, given that in all areas measured the types of crime have changed after the improvement of environmental conditions, resulting in those who usually commit certain wrongdoings to abandon their way of operating and opt in their desperation for and even move to other areas to commit crimes according to the modus operandi used even before the interventions.

In addition, the development and implementation of situational prevention methodologies and CPTED has managed to reduce the occurrence of vandalism in the sectors where these strategies have been implemented, significantly improving citizen participation, social cohesion and increasing the use of public spaces and green areas by the community.

Finally, it is essential to note that both situational prevention strategies and CPTED manage to reduce the perception of insecurity of the population, a fact that is reflected in the graph below, where the results are appreciated related to the level at which crime affects the quality of life of people, and where in Pedro Aguirre Cerda, who's were very affected by the crimes, were reduced by amount from $87 \%$ to $57.1 \%$ after the implementation of improvements in the average design environmental of the territory.

Similarly, in the La Laguna sector in Honduras, those who reported feeling really affected by crime in their daily lives, decreased by $5,8 \%$ between the first and second measurements.

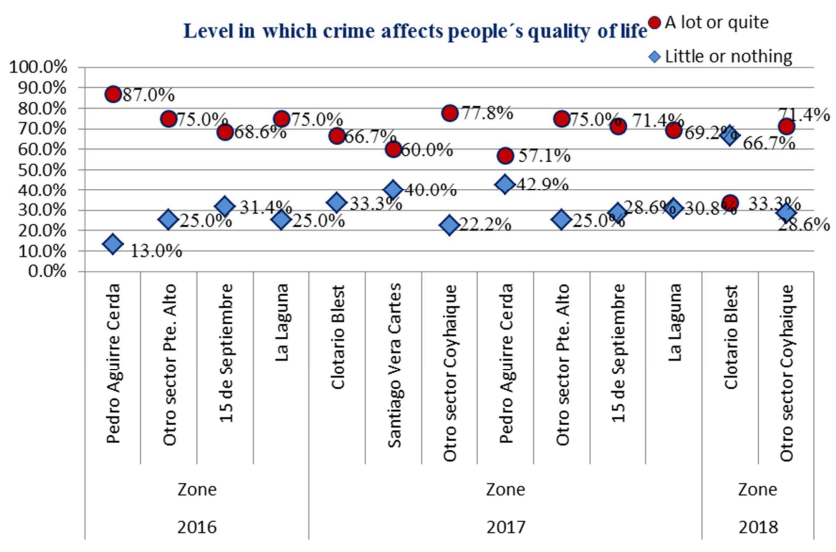

Figure 10. On the level at which crime affects people's quality of life. Data compared to 2016, 2017 and 2018. Source: Victimization questionnaire, perception of insecurity and environmental variables (ESU). 
Finally, in the case of Clotario Blest in Chile, the percentage decrease for people who reported feeling very affected by crime in their daily lives is quite important after the implementation of situational prevention methodologies and CPTED, since in the first measurement these cases reached $66.7 \%$ and in 2018 this percentage was reduced to $33.3 \%$.

\section{Conclusions}

\subsection{Specific Conclusions}

Since the beginning of this investigation, several results have been identified, one of which is related to the fact that the installation of luminaires in the Pedro Aguirre Cerda area, in the commune of Puente Alto, not only reduced the fear of the community and, therefore, the living conditions of the inhabitants of the territory improved, since in turn they improved the levels of confidence that exists among the neighbors, as expressed in the following hypothesis test:

Through the "chi square" hypothesis test for ordinal and/or nominal variables, it is possible to establish that there is statistically significant evidence. 0.011 to reject the null hypothesis and to assert that there is an association between "the installation of public luminaires" and "the level of trust between neighbors".

Table 4. Chi-square hypothesis test for ordinal and/or nominal variables.

\begin{tabular}{llllll}
\hline Chi-Squared tests & & & & & \\
\hline & Values & gl & Sig. asymptotic (2 sides) & Exact Significance (2 sides) & Exact Significance (1 side) \\
\hline Pearson Chi-squared & $6,420^{\mathrm{a}}$ & 1 &, 011 & & \\
Continuity Correction & 5,526 & 1 &, 019 &, 017 &, 010 \\
Likelihood ratio & 6,216 & 1 &, 013 & & \\
Fisher's exact test & & & & & \\
Linear association by linear. & 6,384 & 1 & 012 & \\
Number of valid cases & 178 & & &
\end{tabular}

a. 0 boxes $(0,0 \%)$ have expected a count less than 5 . The expected minimum count is 15,08 .

b. Only calculated for a table $2 \times 2$.

Another important aspect relates to the fact that the existence or absence of enlightenment is linked to the specific place where the criminal acts occurred, that is, in the absence of public enlightenment in certain specific places, they are presented conditions for this purpose. Crimes are committed, whereas before the installation of new lighting lamps in places that lacked these elements, the crime is transferred from these sectors to places where there is less visibility.

Through the "chi square" hypothesis test for ordinal and/or nominal variables, it is possible to establish that there is statistically significant evidence. 0.049 to reject the null hypothesis and to assert that there is an association between "the installation of public luminaires" and "the specific place of occurrence of crimes".

Based on the diagnosis applied in Puente Alto, it is also possible to conclude that the lack of lighting is directly associated with the occurrence of homicides, while the implementation of Situational Prevention and CPTED projects that contemplate the incorporation and renovation of public luminaries such as the developed in 2016 in this district, contribute directly, for example, to the use playgrounds in the squares and parks of the sector.

In the case of Honduras, and more specifically in measurements made in the populations of Tela, there is a high perception of insecurity at bus stops and on public transport. This fact is attributed by the neighbors to the poor distribution of police personnel in the area, since although they recognize that there is a police presence of municipal guards in these territories, they point out that they are not permanently located in the places where they should be.

As expressed in the following hypothesis test, the presence or absence of police mobiles in the sectors involved is directly associated with the victimization of people in the different measured localities, both in Chile and Honduras, which allows to evaluate some aspects not intervened through the methodologies of Situational Prevention and CPTED, as these do not require structural or physical modifications of the territories, but where planning work can be carried out on security issues to optimize the distribution of the human resource that provides support and security to the community in the most at-risk sectors.

Through the "chi square" hypothesis test for ordinal and/or nominal variables, it is possible to establish that there is statistically significant evidence. 0.000 to reject the null hypothesis and to assert that there is an association between "the presence or absence of police mobiles" and "having been the victim of a crime during the last twelve months".

Another important finding identified in the localities of Honduras, which can also be extrapolated to other communities with similar sociodemographic characteristics, is that in the city of La Laguna there are well-defined accesses for the population, i.e. there is no dark nooks and crannies, which do not have alternative routes, while in the colony 15 September, a sector that was used as a control group, a high percentage of people indicate that the urban configuration of this sector has characteristics that favor the concealment of people whose purpose is to commit some kind of crime, thus increasing the feeling of fear and the perception of insecurity. From the data, and by testing a "chi-square" hypothesis for ordinal and/or nominal variables, it was possible to establish that there is statistically significant evidence. 0.004 to reject the null hypothesis and to assert that there is an association between "the existence of well-defined access to the population" and "the fear of being the victim of a crime", especially in squares, parks and recreation sites.

While there are some problems associated with public 
transport, the distribution of human resources and the urban configuration of some localities in the city of Tela, there is still a low victimization, a fact that can be attributed mainly to the permanent presence of police personnel and the municipal guard in this territory.

This is verified through the following hypothesis test:
From the data, and by testing a "chi-square" hypothesis for ordinal and/or nominal variables, it was possible to establish that there is statistically significant evidence. 0.012 reject the null hypothesis and assert that there is an association between "the existence of police mobiles" and "the level at which crime affects people's quality of life".

Table 5. Chi-square hypothesis test for ordinal and/or nominal variables.

\begin{tabular}{llll}
\hline chi-squared tests & & gl & Sig. asymptotic (2 sides) \\
\hline & Value & 3 &, 012 \\
Pearson's chi-squared & $10,909^{\text {a }}$ & 3 &, 010 \\
Likelihood ratio & 11,305 & 1 &, 003 \\
Linear association by linear & 8,610 & 190 & \\
Number of valid cases & 190 & \\
\hline
\end{tabular}

a. 0 boxes $(0,0 \%)$ have waited for a count of less than 5 . The expected minimum count is 12,93 .

In the commune of Coyhaique, the emphasis of interventions using the CPTED methodology was given by the search for road connectivity, community participation and social cohesion. In addition, projects related to the installation of lighting and infrastructure, such as a roofed football field and children's games, were developed.

Through hypothesis tests with "chi-square" for ordinal and/or nominal variables, it was possible to establish that there is statistically significant evidence to reject null hypotheses and to assert that there is an association between the implementation of "measures alongside neighbors," such as exchanging phone numbers and forming surveillance systems, and "reducing the perception of insecurity." It is for this reason that the implementation of comprehensive security strategies is indispensable, since in addition to changes in urban infrastructure, psychosocial prevention programmes are developed that contribute to reducing risk factors socio-criminals present in communities.

As for the installation and improvement of the public infrastructure in the case of the Multi-court, through a hypothesis test it was possible to establish that the improvement of the sports venue and additional equipment, generates a higher quality of life for the population, greater participation, more social cohesion and, therefore, greater tools that together are useful for dealing with crime.

From the data, and by testing "chi-square" hypotheses for ordinal and/or nominal variables, it was possible to establish that there is statistically significant evidence of 0.003 to reject the null hypothesis and to assert that there is an association between the "installation of football fields" and "the level at which crime affects people's quality of life."

At the same time, the improvement of the sports infrastructure fostered the trust between the neighbors and the use of public spaces by them, a fact that was also corroborated by the conduct of hypothesis tests.

It is important to mention that in the Clotario Blest population of Coyhaique, during the 2017 measurement, there were no cases of persons who had been victims of any crime during the last twelve months, however, in the second measurement and after the intervention through CPTED methodologies, this percentage of victimization increased to $18.8 \%$ in 2018 , a fact that is attributed to the increase in the confidence of the population to make complaints after the measurements made, also due to the interest of authorities on the issue of security and infrastructure interventions using CPTED intervention methods.

On the other hand, one of the contradictions that is generated in this area after both measurement stages is that while the percentage of people victims in 2018 increases relative to the data collected in the previous year, there is a decrease in the perception of insecurity, both in the population of Clotario Blest, which was intervened, and in "Other sectors of Coyhaique" that were used as control groups.

The latter fact relates mainly, at least in the Clotario Blest population, to improvements in road connectivity made through CPTED methodologies, in addition to lighting projects, installation of children's games and installation multi-court roofed, among other actions linked to a thorough psychosocial work. This package favored community participation, the appropriation of public spaces and social cohesion in this area, while reducing the perception of insecurity of the population residing in that territory.

Other aspects that also generate a lot of concern in the communities where the impact measurement of the Situational Prevention and CPTED methodologies was developed, says relation to incivilities and risk factors, as these have a direct impact on victimization and the perception of fear of the population, therefore, are necessary topics to address.

As a result of the above, and by testing "chi-square" hypotheses for ordinal and/or nominal variables, it was possible to establish that there is statistically significant evidence of 0.038 to reject the null hypothesis and assert that there is an association between "alcohol consumption in the public space" and "the fact that there are people who have been victims of crime during the last twelve months in the area."

\subsection{General Conclusions}

Based on the evidence obtained, it can be noted that the methodologies of Situational Prevention and CPTED actually have an impact on the reduction of crimes of greater social connotation, including theft and homicides. In addition, through the implementation of these methods of intervention, the occurrence of incivilities, increase social cohesion and 
improve community participation can be reduced, while contributing to a better quality of life for people.

On the other hand, the implementation of projects associated with the methodologies of Situational Prevention and CPTED, contribute to decrease the perception of insecurity in the population, even more so if these interventions incorporate a deep psychosocial work. This, because by not intervening in a territory in an integral way, it is possible to influence the reduction of the perception of fear, but not necessarily on the incidence of crime.

The impact assessment methodology proposed in this research, emphasizes community participation, since it considers the inhabitant of urban space as "native expert" of their environmental security, and therefore should be a key player in all components of the prevention strategy, being considered as opposed to conventional impact assessment methods, so that in the different phases you can deliver your perception regarding citizen security issues using different techniques collection of information, the nature of which may be of quantitative and/or qualitative origin.

Finally, this descriptive and comparative statistical work, based mainly on measurements made at the previous and subsequent time of situational Prevention and CPTED interventions, is complemented by the development of hypothesis tests statistics, which seek to establish associations between variables to verify whether there is indeed statistically significant evidence to affirm or reject the existence of associations between the different variables extracted from the ESU questionnaire, thus identifying, for example, what improvements in urban configuration are associated with the decrease in the sense of fear in the population of a given territory.

\subsection{Specific Conclusions}

Since the development of this research, interesting findings have been identified. One of them relates to the fact that the installation of luminaires in the Pedro Aguirre Cerda population of the commune of Puente Alto, not only managed to reduce the feeling of fear in the community and therefore improve the living conditions of the inhabitants of the territory, since it also improved levels of trust among community members, as expressed in the following hypothesis test:

Through the "chi square" hypothesis test for ordinal and/or nominal variables, it is possible to establish that there is statistically significant evidence following. 0.011 to reject the null hypothesis and to assert that there is an association between "the installation of public luminaires" and "the level of trust between the neighbors".

In the commune of Coyhaique, meanwhile, the emphasis of interventions using CPTED methodology was given by the search for road connectivity, community participation, social cohesion, lighting and infrastructure projects, such as Multi-roofed court and children's games.

In the case of multi-court, through a hypothesis test it was possible to establish that the improvement of the sports venue and additional equipment, generates greater quality of life for the population, greater participation, more social cohesion and therefore, greater tools to tackle the crime.

From the data, and through a "chi-square" hypothesis test for ordinal and/or nominal variables, it was possible to establish that there is statistically significant evidence following. 0.003 to reject the null hypothesis and to assert that there is an association between "installation of football pitches" and "the level at which crime affects people's quality of life".

In turn, the improvement of the sports infrastructure led to the trust between the neighbours and the use of public spaces by them, a fact that was also corroborated through the conduct of hypothesis tests where the crossing of these Variables.

Other aspects that also generate a lot of concern in the communities where the impact measurement of the Situational Prevention and CPTED methodologies was developed, says relation to incivilities and risk factors, as these have a direct impact on victimization and the perception of fear of the population, therefore, are necessary topics to address.

As noted below, through a "chi-square" hypothesis test for ordinal and/or nominal variables, it was possible to establish that there is statistically significant evidence following. 0.038 to reject the null hypothesis and to assert that there is an association between "alcohol consumption on public roads" and "the fact that it has been the victim of a crime during the last twelve months", a situation that occurs in all the localities in this study.

Another important fact identified in this study relates that a comprehensive model of territorial intervention for crime prevention has a more significant impact on crime reduction and the perception of fear in relation to crime interventions that consider only changes in the urban infrastructure of the intervened territories. An example of this is the case of Puente Alto, where in the Pedro Aguirre Cerda population a significant decline was achieved in terms of victimization and perception of fear, since precisely the methodology implemented in that territory in addition to urban variables involved the incorporation of psychosocial programs that developed in parallel, seeking to unravel the causes of crime in a targeted territory.

Finally, a final reflection on the issues covered in this research relates to the fact that it is essential to have the absolute political will to support urban security strategies to guide and focus resources to projects that involve changes in urban configuration and in turn develop psychosocial prevention in the same territory.

Emphasis is placed on this last point, since as has been reiterated in the course of this study, the focus of resources for CPTED strategies and Situational Projects, which also have the development of interventions with psychosocial characteristics, they can lead to further crime reduction and give greater notoriety to the decline in perception of fear in the population. Fact that was demonstrated in the case of the Pedro Aguirre Cerda population in the commune of Puente Alto. 


\section{References}

[1] Blanco, J., \& Vargas, G. (2010). Participación en políticas de seguridad ciudadana. Santiago: En foco. ISSN 0717-9987.

[2] Ekblon, P. (2012). Citizen participation in crime prevention capturing practice Knowledge through the 5ls framework. Londres.

[3] Felson, C. \&. (1998). Prevención Situacional del Delito. Police Research Series, Paper 98.

[4] Hernández, R., Fernández, C., \& Baptista, P. (2010). Metodología de la Investigación. Mc Graw Hill.

[5] Jeffery, C. R. (1971). Crime Prevention Through Environmental Desingn. Beverly Hills (California): Published by Sage Publications, Inc.

[6] National Institute of Statistics. (2017). National Urban Citizen Safety Survey. Santiago: https://www.ine.cl/docs/default-source/sociales/seguridad-ciud adana $/ 2017 /$ metodolog $\% \mathrm{C} 3 \% \mathrm{ADa} / 180514$ sintesis_de_result ados_xiv_enusc_2017_ajs.pdf.

[7] Newman, O. (1996). Creating Defensible Space. Institute for Community Design Analysis. U.S.: Department of Housing and Urban Development Office of Policy Development and Research.

[8] Rau, M. \&. (2008). PREVENCION DE LA VIOLENCIA Y EL DELITO MEDIANTE EL DISEÑO AMBIENTAL EN LATINOAMÉRICA Y EL CARIBE: Estrategias Urbanas de Cohesión Social e Integración Ciudadana. Revista INVI Universidad de Chile, 169-189.

[9] Rau, M. \&. (2010). Impact Assessment Studies for Situational Prevention Methodologies and CPTED. Latin-American y El Caribe: International CPTED Association ICA.

[10] Rau, M. (2019). Perception of Criminal Insecurity in
Vulnerable Districts Latin America. Social Sciences, Manuscript ID: SOCSCI-465268.

[11] Rodríguez, J., \& Quinde, M. (2016). Miedo al delito y medios de comunicación tradicionales: Un estudio exploratorio con universitarios venezolanos. Escuela de Criminología. Venezuela: Universidad de Los Andes. Facultad de Piscología.

[12] Roncek, D., \& Bell, P. (1981). Bars, Blocks and crime. Environmental Systems. Department of Sociology, California Satate. California, USA: Stockdale Highway, Bakersfield, CA, 93309.

[13] Sabatini, F. (1998). Nociones de una ciudadanía que crece. Santiago: Serie libros FLACSO ISBN. 956-205-126-9.

[14] Schindler, V. (2005). Estándares Beccaria. Consejo federado para la prevención en baja Sajonia. Francia.

[15] Serrano, A. \&. (2007). Tendencias en delincuencia y percepción social de la inseguridad ciudadana en España y la Unión Europea. Madrid: Edisofer, S. L.

[16] United Nations Development Program. (2013). Regional Human Development Report. Citizen Security With Human Face: Diagnosis and proposals for Latin America. New York: UNDP.

[17] Van Soomeren, P. (2018). Global CPTED Standarization Report. Millford, Connecticut. USA: ICA.

[18] Vilalta, C., \& Castillo, J. \&. (2016). Delitos violentos en ciudades de América Latina. Santiago: Banco Interamericano de Desarrollo.

[19] Vozmediano, L., San-Juan, C., \& Vergara, A. \&. (2013). Risk perception in digital contexts: questionnaire and pilot study. International E-JOURNAL of Criminal Sciences, 1-18.

[20] World Health Organization. (2002). Global report on violence and health. Washington D. C: Panamerican Health Organization for World. 